\title{
Surgical treatment of partial anomalous pulmonary venous connection to the superior vena cava
}

\author{
Tratamento cirúrgico da conexão anômala parcial das veias pulmonares em veia cava superior
}

Marcelo Dagola PAULISTA, Paulo Henrique Dagola PAULISTA², Ana Luiza Paulista GUERRA³, Paulo Paredes PAULISTA $^{4}$

\section{Abstract}

Objectives: Surgical treatment of anomalous pulmonary venous connection to the superior vena cava, associated with sinus venous atrial septal defect, is well established and presents with low morbidity and mortality. In order to reduce the incidence of stenosis or occlusion of the right superior vena cava, especially when associated with the presence of left superior vena cava, the right atrial appendage was used to enlarge the right superior vena cava, after the diversion of the anomalous pulmonary veins to the left atrium.

Methods: Between June 1986 and September 2008, 95 consecutive patients with anomalous drainage in the superior right vena cava and high right atrium underwent surgery. Ages ranged from 6 months to 68 years and females predominated with 50 cases.

Results: There was no death in the immediate or late postoperative period. The sinus cardiac rhythm was preserved in all cases and there was no complications in the late follow-up.

Conclusion: This study shows the applicability of the technique described with favorable results on mortality, rhythm disturbances and complications in the right superior vena cava.

Descriptors: Cardiovascular abnormalities. Congenital abnormalities. Cardiovascular surgical procedures. Vena cava, superior. Heart defects, congenital/surgery.
1. Lato Sensu Post-graduation in Cardiovascular Surgery, Cardiovascular Surgeon Physician of the Team of Dr. Paulo P. Paulista at the Real e Benemérita Associação Portuguesa de Beneficência.

2. Cardiovascular Surgery Specialization Course of the Dante Pazzanese Institute of Cardiology, Cardiovascular Surgeon Physician of the Dante Pazzanese Institute of Cardiology.

3. Specialist in Intensive Therapy at the Brazilian Society of Intensive Therapy; Head of the Congenital Cardiopaty Postoperative Unit of the Intensive Therapy Unit of the Dante Pazzanese Institute of Cardiology.

4. Titular Member of the Brazilian Society of Cardiovascular Surgery; Cardiovascular Surgeon of the Dante Pazzanese Institute of Cardiology.
This study was carried out at the Hospital da Real e Benemérita Associação Portuguesa de Beneficência and Dante Pazzanese Institute of Cardiology, São Paulo, SP, Brazil.

Correspondence address:

Marcelo Dagola Paulista. Rua da Consolação, 3625 - $9^{\circ}$ andar - São Paulo, SP, Brazil - CEP: 01416-020

E-mail: paredespaulista@hotmail.com 
Resumo

Objetivo: O tratamento cirúrgico da conexão anômala das veias pulmonares em veia cava superior, associada ao defeito septal atrial tipo seio venoso, é bem estabelecido e transcorre com baixa mortalidade e morbidade. Com a finalidade de diminuir a incidência de estenose ou oclusão da veia cava superior direita, especialmente quando associada à presença de veia cava superior esquerda, o apêndice atrial direito foi utilizado para ampliar a veia cava superior direita, após o desvio das veias pulmonares para o átrio esquerdo.

Métodos: No período entre junho de 1986 e setembro de 2008, foram operados 95 pacientes, consecutivos, portadores desta anomalia com drenagem em veia cava superior direita e porção alta do átrio direito. A idade variou de 6 meses a 68

\section{INTRODUCTION}

The defects of the atrial septum are common among congenital heart diseases. The most common type is the interatrial communication called "ostium secundum" located at the fossa ovalis. The second in incidence is the type known as "ostium primum", which usually is part of the defect in the atrioventricular septum, located near the atrioventricular valves. Finally, the less frequent interatrial communication (incidence of 10 to $20 \%$ of atrial defects) is called "sinus venous', located in the upper portion of the septum, near the cavo-atrial junction and resulted from embryonary failure in formation and septation of the sinus venous, from which its name is derived [1].

The sinus venous-type defects are characterized by the association to the failure of one or more pulmonary veins of the right lung upper lobe to connect to the left atrium during fetal development. As a result, these anomalous veins may drain part of the right lung directly into the right atrium, right superior vena cava or into other tributary veins $[2,3]$ such as the inferior vena cava, innominate vein or left superior vena cava (cardinal vein), whose persistence around $10 \%$ - may be cause of postoperative complications.

The anomalous venous drainage of the entire right lung or part of it into the inferior vena cava, known as the Cimitarra syndrome, will not be the object of our study.

In this study we assessed the surgical results of the correction of the partial anomalous connection of pulmonary veins in superior vena cava by using the technique of enlargement of the superior vena cava with the right atrial appendage after redirection of anomalous pulmonary veins to the left atrium, by using preserved bovine pericardial patch. Cooley and Spier [4] called this intervention of atriocavoplasty and published their initial experience in 1982. anos e o sexo feminino predominou com 50 casos.

Resultado: No material apresentado, não ocorreu nenhum óbito na fase de pós-operatório imediato ou tardio. $O$ ritmo cardíaco permaneceu sempre sinusal e não ocorreram complicações na evolução.

Conclusão: O presente trabalho demonstra a aplicabilidade da técnica descrita, com resultados favoráveis em relação a mortalidade, distúrbios de ritmo e complicações na região da veia cava superior direita.

Descritores: Anormalidades cardiovasculares. Anormalidades congênitas. Procedimentos cirúrgicos cardiovasculares. Veia cava superior. Cardiopatias congênitas/cirurgia.

\section{METHODS}

From June 17, 1986 to September 5, 2008, 95 consecutive patients underwent correction of partial anomalous connection of pulmonary veins in right superior vena cava and upper portion of the right atrium, in the hospitals Real Benemérita Associação Portuguesa de Beneficência and Dante Pazzanese Institute of Cardiology, both in São Paulo, SP. Of these patients, 50 were females and 45 were men. The median age was 15 years, ranging from 6 months to 68 years, and the weight ranged from 5 to 96 kilograms, with a median of 43 kilograms. The first operation of the series was performed at the Hospital da Beneficência Portuguesa.

\section{Surgical technique}

The surgery was performed via median transsternal thoracotomy with the patient in the dorsal decubitus position and endotracheal intubation, controlled ventilation and with catheters to monitor central venous pressure and arterial pressure. We also monitored the electrocardiogram, the oropharyngeal and rectal temperature and urine output.

The exposure of the heart was performed by longitudinal opening of the pericardium, and after prior systemic heparinization, the cardiopulmonary bypass was installed through the placement of the infusion arterial cannula in the ascending aorta and cannulation of the inferior and superior venae cavae, separated, and the latter very high, above the drainage of the pulmonary veins in the superior cava, near the outflow of the innominate vein or in itself. It is desirable to expose by dissection the entire superior vena cava, the root of the anomalous pulmonary veins and the right azygos vein.

With arterial perfusion stabilized and body temperature around $34^{\circ} \mathrm{C}$, aortic cross clamping, drainage of the left 
atrium and administration of antegrade cardioplegic solution with cold blood at $4^{\circ} \mathrm{C}$ and placement of amorphous ice in the pericardium were performed. This protection was repeated every 30 minutes.

The surgical exposure (Figure 1) was performed by longitudinal incision initiated at the apex of the right atrial appendage, maintained in its edge and directed to the anterior wall of the superior vena cava, by extending it cephalically until widely exposure of the sinus venous-type interatrial communication and outflow of the anomalous pulmonary veins (Figure 2).

The septal defect was corrected using patch of bovine pericardium or autologous or polytetrafluoroethylene, by tunneling the anomalous pulmonary veins through the venous sinus - which was extended if necessary, or created if it was not present - to the left atrium (Figure 3).

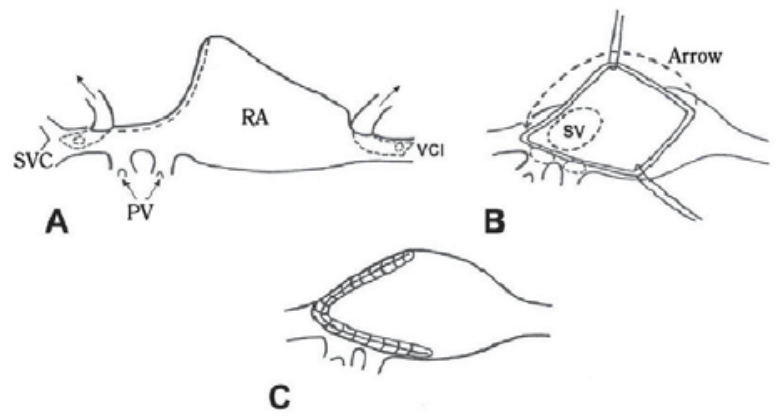

Fig. 1 - Surgical scheme showing in dotted lines in A the surgical incision that moves across the superior vena cava (SVC). In $B$, the wide exposure of the sinus venosus (SV) and anomalous drainage of pulmonary veins $(P V)$. In $C$, appearance of the enlargement of the superior vena cava with the right atrial appendage (arrow). $I V C=$ inferior vena cava; $R A=$ right atrium. Modified from Cooley and Speir [4]

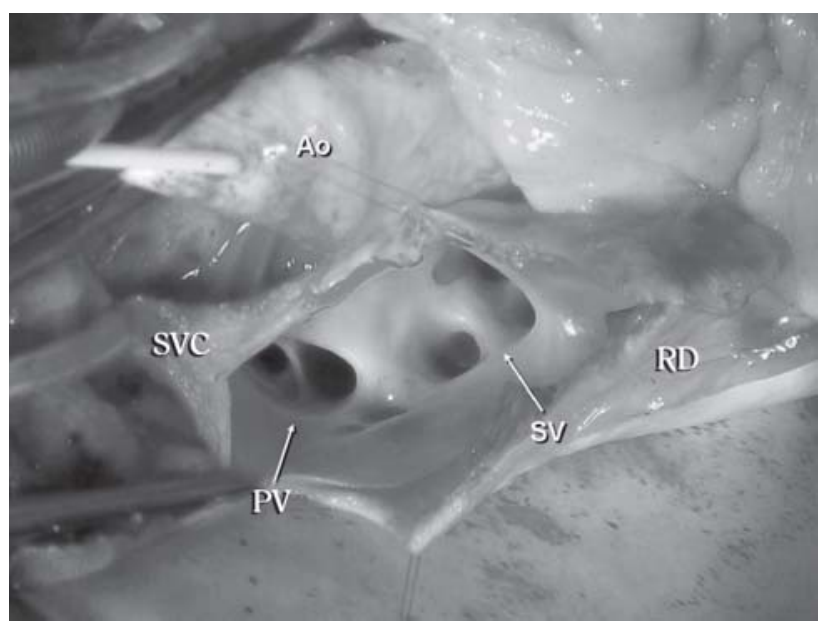

Fig. 2 - Surgical appearance with incision from the apex of the right atrial appendage to the superior vena cava (SVC) and wide exposure of the anomalous pulmonary veins $(P V)$ and the sinus venous-type interatrial defect $(S V) . R D=$ right atrium, $A o=$ aorta

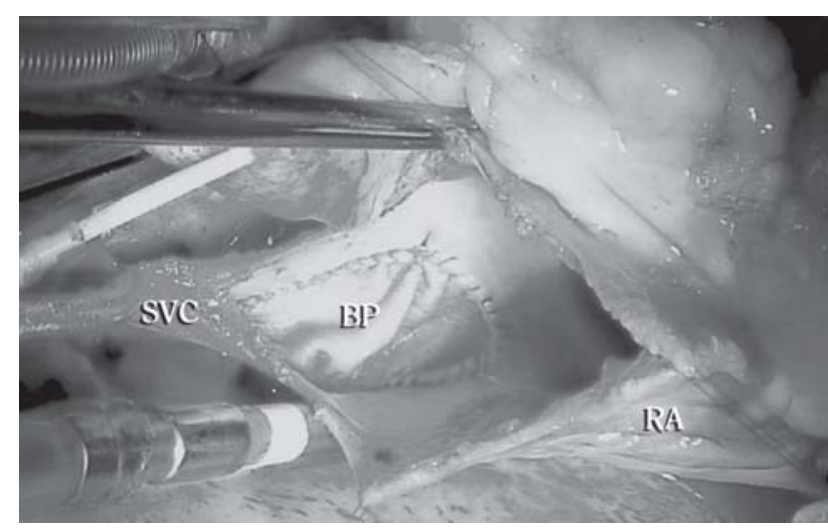

Fig. 3 - Surgical appearance showing bovine pericardial patch (BP) completely closing the interatrial defect and directing the anomalous pulmonary veins to the left atrium. SVC = superior vena cava; $R A=$ right atrium

To avoid the repair of the superior vena cava by right suture of its edges or its enlargement using foreign tissue, which could retract and lead to local stenosis, at that moment the atriocavoplasty was performed.

For this, the incised superior vena cava was entirely enlarged, using the right atrial appendage that was lead to the distal apex of the incision of the superior vena cava and sutured across the extension on its sides (Figure 4). With this simple maneuver, the region was enlarged with patient's own tissue, with maintenance of its blood flow and without occurrence of fibrosis or local retraction. The surgical incision at the edge of the atrial appendage was removed from the sinus node and thus rhythm disturbances were avoided.

After the main time, air was carefully removed from the right and left cardiac chambers, the aorta was unclamped and the beats were recovered. Also, the patient was reheated and disconnected from the perfusion. The review and closure of the chest were performed in an usual manner.

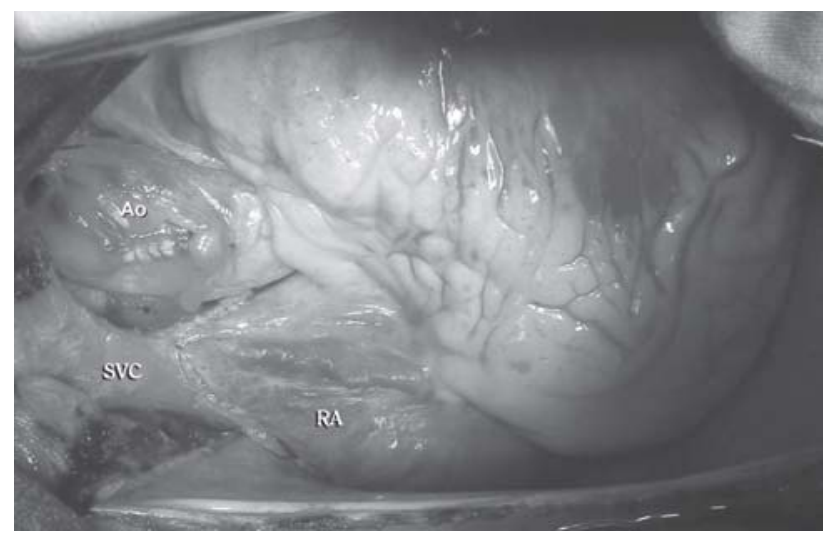

Fig. 4 - Surgical appearance of the enlargement of the superior vena cava $(S V C)$ with the right atrial appendage. $R A=$ right atrium, Ao $=$ aorta 


\section{RESULTS}

In our experience, with the surgical treatment of partial anomalous connection of the pulmonary veins in superior vena cava and high portion of the right atrium, 95 patients underwent surgery through the technique described, from June 1986 to September 2008. The surgical procedure used was the same, without no deaths in hospital or late stage. Only one patient had no sinus venous-type interatrial communication and the interatrial septum was intact.

At the beginning of the series the diagnosis was hemodynamic and, currently only echodopplercardiographic.

Ages ranged from 6 months to 68 years and the rhythm was always sinus at the hospital discharge and in late verification, [5] except for one patient who initially showed junctional rhythm, spontaneously reverted to sinus. There was no use of pacemaker in any patient or need for reoperation.

\section{DISCUSSION}

After the cardiovascular surgeons have abandoned their reluctance to use patches of different materials to correct intracardiac defects, the correction of partial anomalous drainage was also resolved, by tunneling its outflow into the superior vena cava to left atrium. However, the closure of the incision most often used, which is the right lateral atriotomy, extended to the superior vena cava, has became to present fibrosis at the site of direct suture of these structures, with subsequent stenosis or even occlusion of the superior vena cava [ 4].

This occurrence is more frequent when the left superior vena cava is persistent, because it occurs a diversion of blood from the right superior vena cava, which then shows smaller caliber and presents higher tendency to stenosis or occlusion to be split longitudinally during surgery. The use of foreign material enlarging the region in order to alleviate the problem does not seem to be solved it completely [6,7].

To avoid these complications, in 1984, Warden et al. [8] and, posteriorly, Gustafson et al. [9], reported a technique in which the superior vena cava is sectioned above the outflow of the highest anomalous pulmonary vein and the distal or cephalic stump is anastomosed in the right atrial appendage. The proximal or caudal stump is then sutured through blind technique - in order to drain the anomalous pulmonary veins, through the sinus venous-type interatrial communication to the left atrium through the use of patch of bovine pericardium or similar (Figure 5).

Due to the occurrence of cases of obstruction of superior vena cava with this technique, some authors seek to enlarge the superior vena cava outflow in the right atrial appendage using pedicled autologous pericardium. Even with this technique and its modification by enlarging the region, the authors describe cases of stenosis or occlusion of superior vena cava especially when the left superior vena cava was persistent [5]. A possible cause of stenosis of the superior vena cava is the need to bring the cephalic stump of superior vena cava up to the right atrial appendage. Despite the extensive mobilization of the superior vena cava and innominate vein, tension in these structures may be persistent leading to the lesions described. The use of expanded polytetrafluoroethylene tube or similar is recommended by some authors, which probably ends up being the cause of new problems.

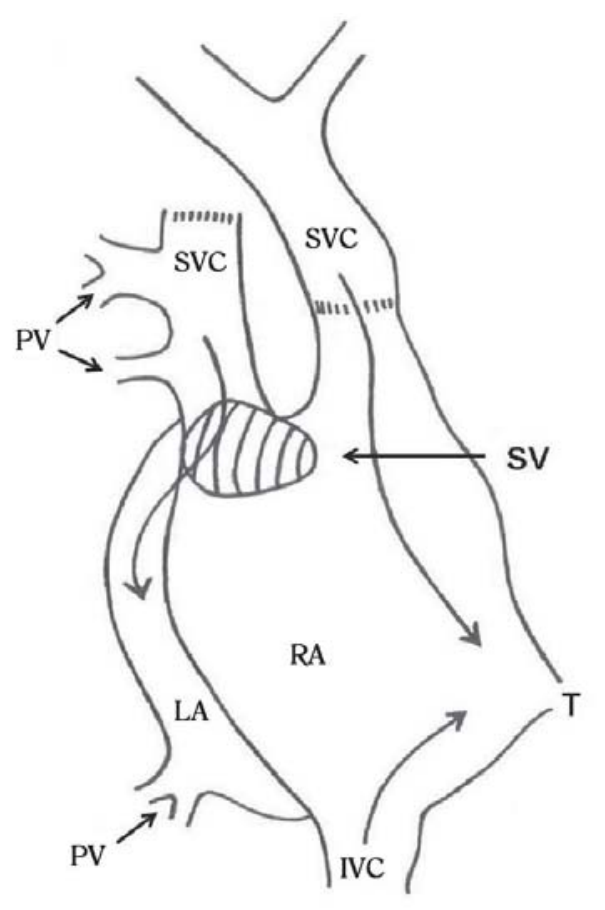

Fig. 5 - Procedure on which the superior vena cava is sectioned above the outflow of the highest anomalous pulmonary vein and the distal or cephalic stump is anastomosed in the right atrial appendage. $S V C=$ superior vena cava, IVC = inferior vena cava; $R A=$ right atrium, $L A=$ left atrium; $T=$ tricuspid valve, $P V=$ pulmonary vein, $S V=$ sinus venosus closed with bovine pericardium. Modified from Nakahira et al. [6]

\section{CONCLUSION}

Surgical correction of partial anomalous connection of pulmonary veins in superior vena cava, associated or not with sinus venous-type interatrial communication, is a well established procedure with low mortality and morbidity and good long-term results. 
There are several possible techniques to be employed in most of the cases. This study aims to demonstrate the applicability of the technique described, with favorable results, especially with regard to mortality, rhythm disturbances and complications in the right superior vena cava.

\section{ACKNOWLEDGMENTS}

To Maria Helena Lombardi and Carlos Santiago Batista Ordoñez Antezana, for the assistance in preparing this study.

\section{REFERENCES}

1. Schuster SR, Gross RE, Colodny AH. Surgical management of anomalous right pulmonary venous drainage to the superior vena cava, associated with superior marginal defect of the atrial septum. Surgery. 1962;51:805-8.

2. Healey JE Jr. An anatomic survey of anomalous pulmonary veins: their clinical significance. J Thorac Surg. 1952;23(5):433-44.
3. Kirklin JW, Barrat-Boyes BG. Atrial septal defect and parcial anomalous pulmonary venous connection. In: Kirklin JW, Barrat-Boyes BG, eds. Cardiac surgery. 2nd ed. Vol 1. New York:Churchill Livingstone;1993. p:627-30.

4. Cooley DA, Speir AM. Atrio-cavoplasty for repair of sinus venosus atrial defect. Tex Heart Inst J. 1982;9(1):37-40.

5. Buz S, Alexi-Meskishvili V, Villavicencio-Lorini F, Yigitbasi M, Hubler M, Weng Y, et al. Analysis of arrhythmias after correction of partial anomalous pulmonary venous connection. Ann Thorac Surg. 2009;87(2):580-3.

6. Nakahira A, Yagihara T, Kagisaki K, Hagino I, Ishizaka T, Koh $\mathrm{M}$, et al. Partial anomalous pulmonary venous connection to the superior vena cava. Ann Thorac Surg. 2006;82(3):978-82.

7. Friedli B, Guérin R, Davignon A, Fouron JC, Stanley P. Surgical treatment of partial anomalous pulmonary venous drainage. A long-term follow-up study. Circulation. 1972;45(1):159-70.

8. Warden HE, Gustafson RA, Tarnay TJ, Neal WA. An alternative method for repair of partial anomalous pulmonary venous connection to the superior vena cava. Ann Thorac Surg. 1984;38(6):601-5.

9. Gustafson RA, Warden HE, Murray GF. Partial anomalous pulmonary venous connection to the superior vena cava. Ann Thorac Surg. 1995;60(6 Suppl):S614-7. 